OPEN ACCESS

Edited by:

Laszlo Csiba,

University of Debrecen, Hungary

Reviewed by:

Ivana Galinovic,

Center for Stroke Research Berlin (CSB), Germany

Manabu Inoue,

National Cerebral and Cardiovascular

Center, Japan

*Correspondence:

Tomáš Dorňák

dornaktomas@seznam.cz orcid.org/0000-0002-5111-3617

Specialty section:

This article was submitted to

Stroke,

a section of the journal

Frontiers in Neurology

Received: 16 January 2019

Accepted: 05 April 2019

Published: 26 April 2019

Citation:

Dorňák T, Král M, Šaňák D and Kaňovský P (2019) Intravenous

Thrombolysis in Posterior Circulation

Stroke. Front. Neurol. 10:417.

doi: 10.3389/fneur.2019.00417

\section{Intravenous Thrombolysis in Posterior Circulation Stroke}

\author{
Tomáš Dorňák*, Michal Král, Daniel Šaňák and Petr Kaňovský \\ Department of Neurology, Palacky University and University Hospital, Olomouc, Czechia
}

Background: Intravenous thrombolysis (IVT) is a standard treatment for both anterior circulation ischemic stroke (ACIS) and posterior circulation ischemic stroke (PCIS). PCIS is a clinical syndrome associated with ischemia-related changes in the territory of the posterior circulation arteries. Embolism is the most common stroke mechanism in posterior circulation. PCIS represents 12-19\% of all IVT-treated strokes.

Methods and Results: We searched the PubMed database for assessments of intracerebral hemorrhage $(\mathrm{ICH})$ and clinical outcome in PCIS patients treated with IVT. $\mathrm{ICH}$ occurs in 0-6.9\% of posterior ischemic stroke depending on the definition of symptomatic $\mathrm{ICH}$, and any $\mathrm{ICH}$ in $17-23.4 \%$ of posterior ischemic stroke. For patients with PCIS, 38-49\% have a favorable outcome (mRS 0-1) after IVT. Better clinical outcomes occur more often in patients with PCIS than in those with ACIS. The mortality rate among PCIS patients treated with IVT ranges from 9 to 19\%; it does not differ significantly between PCIS and ACIS.

Conclusions: Up to date, no data about PCIS and IVT are available from RTCs. Based on limited results from retrospective clinical studies and case series, IVT is safer for use in PCIS than in ACIS. Patients with brainstem ischemia, vertebral artery occlusion, and absence of basilar or posterior cerebral artery occlusion could be considered for treatment with IVT even in borderline cases. Time to IVT in PCIS seems to be a less crucial factor than in ACIS. IVT for PCIS may be beneficial even after $4.5 \mathrm{~h}$ from symptom onset.

Keywords: stroke, posterior circulation, intravenous thrombolysis, intracranial hemorrhage, ischemia

\section{INTRODUCTION}

\section{History of Intravenous Thrombolysis - The Most Relevant Studies}

Intravenous thrombolysis (IVT) is a standard treatment for both anterior circulation ischemic stroke (ACIS) and posterior circulation ischemic stroke (PCIS). Recombinant tissue plasminogen activator (rtPA, alteplase) was licensed for the first time in 1996 in North America for intravenous use within $3 \mathrm{~h}$. A restricted conditional license for the use of rtPA within $3 \mathrm{~h}$ was granted in Europe in 2002. At the beginning of the rtPA era (1992/1993), three smallplacebo-controlled studies reported its efficacy in the early stages of ischemic stroke (1-3).

Later, three much largerplacebo-controlled trials showed the benefits of intravenous rtPA given to patients with ischemic stroke selected by clinical symptoms and CT. Studies by the National Institute of Neurological Disorders and Stroke (NINDS) and Alteplase Thrombolysis for Acute Noninterventional Therapy in Ischemic Stroke A + B (ATLANTIS) demonstrated improvements in functional outcomes at 3 months if thrombolysis was administered within $3 \mathrm{~h}$ of symptom onset, with the greatest benefit seen within $90 \mathrm{~min}$ from symptom onset $(4,5)$. The European Cooperative 
Acute Stroke Study (ECASS) III trial tested and proposed improvements in clinical outcome after intravenous alteplase administered between 3 and $4.5 \mathrm{~h}$ (6). Five other placebocontrolled trials showed no clear benefit of early rtPA treatment (7-11).

All these studies were done on patients up to 80 years old with a specific type of stroke. The International Stroke Trial (IST 3), a placebo-controlled trial, was initiated to provide evidence for a wide range of patients (12). It reported improved functional outcome up to $6 \mathrm{~h}$ on 3,035 patients. The benefit did not seem to be diminished in elderly patients. In the rtPA group, $37 \%$ of patients were alive and independent, with a $7 \%$ risk for symptomatic intracranial hemorrhage $(\mathrm{sICH})$; in the control group, $35 \%$ of patients were alive and independent, with a $1 \%$ risk for sICH. These questionable results summarized in Table 1 led to greater pressure on patient selection and a search for outcome and sICH predictors.

\section{Definition of PCIS}

PCIS is a clinical syndrome associated with ischemia related to stenosis, in situ thrombosis, or embolic occlusion of the posterior circulation arteries (13). Posterior circulation arteries comprise the territory of the vertebral, cerebellar, posterior cerebral, and basilar artery. ACIS and PCIS differ in several respects: frequency, symptoms and signs, etiology, risk for recurrent stroke, sensitivity, and specificity of diagnostic modalities and prehospital screening instruments, acute management, complication after acute treatment, and clinical outcome (13-20).

\section{Anatomy and Clinical Features}

Posterior circulation comprises the territory of the vertebral arteries, basilar artery, and posterior cerebral arteries. Vertebral arteries and their branches supply blood to the medulla and cerebellum. They are often asymmetric and one is dominant, causing an elongation of the basilar artery to the opposite site (21). The basilar artery is joined to the brainstem by penetrating the caudal, middle, and rostral branches that form anastomoses in 42 to $67 \%$ of the cases (22). Proximal and middle segments, including the anterior inferior cerebellar artery and the superior cerebellar artery, supply the pons and cerebellum; distal segments supply the mesencephalon. The apex of the basilar artery supplies the median and paramedian portions of the midbrain and thalamus. Posterior cerebral arteries supply oxygenated blood to the temporal and occipital lobe, part of the thalamus, the walls of the third ventricle, choroid plexus, cerebral peduncle, fornix, and caudate nucleus (23).

The posterior circulation is rich in collaterals and clinical manifestations of disturbed flow are therefore highly variable $(22,24)$. In addition, symptoms and signs considered typical for PCIS occur far less often than was expected. Inaccurate localization would occur commonly if clinicians relied on the clinical neurological deficits alone $(17,19)$. Among $407 \mathrm{New}$ England Medical Center Posterior Circulation registry patients, the most common symptoms were dizziness (47\%), unilateral limb weakness (41\%), dysarthria (31\%), gait ataxia $(31 \%)$, headache $(28 \%)$, nausea or vomiting $(27 \%)$, and nystagmus $(24 \%)$ $(13,24)$. Numerous eponyms are linked to posterior circulation stroke syndrome, many of which occur in an incomplete form (25). Diverse clinical symptoms of PCIS potentially contribute to a delay in diagnosis. Burns et al. (26) reported the median time from emergency department arrival to diagnosis as $8 \mathrm{~h} 24 \mathrm{~min}$ for basilar artery and $1 \mathrm{~h} 23 \mathrm{~min}$ for left middle cerebral artery.

\section{Pathophysiology and Causes}

In a large single-center study on 407 patients, embolism was the commonest stroke mechanism (40\% of patients including $24 \%$ cardiac origin, $14 \%$ intra-arterial, and $2 \%$ cardiac and arterial sources) (24). Cerebellar infarct without concomitant brainstem or occipital infarct was associated with cardioembolism (67\%); isolated paramedian pontine or midbrain infarct was associated with basilar artery stenosis (71\%) (27). Vertebral artery dissection is a rare cause of stroke in the general population; however, it represents one of the more common causes of stroke in patients younger than 45 years of age. Neck distortions such as chiropractic manipulation, bending of the neck, and blunt trauma cause the dissection (28).The etiology of PCIS appears to be different in non-Caucasians, with a rare $(5.2 \%)$ chance of cardioembolism (27).

\section{Diagnostic Methods}

The recognition of stroke in the prehospital phase and in the emergency room can be done by the Face Arm Speech Test (FAST), ABCD 2, and Recognition of Stroke In the Emergency Room (ROSIER) scales. Both FAST and ABCD2 scores, which have been developed as screening tools for unselected strokes, are less effective in the diagnosis and identification of high-risk cases for PCIS and transitory ischemic attack (TIA) (14). The ROSIER scale seems to be more sensitive to marking PCIS as a potential stroke, because this scale includes a visual field defects evaluation (29). Although still giving more weight to symptoms of anterior circulation stroke, the National Institute of Health Stroke Scale (NIHSS) scale does include PCIS specific symptoms like gait ataxia and visual field loss. It is frequently used in daily clinical practice to categorize severity of stroke. The expanded NIHSS (e-NHISS) might improve the sensitivity of NIHSS for PCIS symptoms (30).

All cases of suspected stroke must be further diagnosed with $\mathrm{CT}$ or magnetic resonance imaging (MRI) to exclude intracranial hemorrhage (ICH). If a patient is a candidate for IVT, then vessel imaging should be done without delay to exclude large vessel occlusion. Acute phase CT imaging is generally more available than MRI. MRI is similar to CT in detecting acute ICH (31). Diffusion-weighted imaging (DWI) done within $3 \mathrm{~h}$ can detect ischemic changes with $73-92 \%$ sensitivity and near $100 \%$ in the first $6 \mathrm{~h}$ after symptom onset (32). MRI is therefore superior to non-contrast CT, which has sensitivity below $20 \%$ within first $3 \mathrm{~h}$ and only $57-71 \%$ in the first $24 \mathrm{~h}$ after onset of stroke $(31,32)$. Thus, MRI can help to diagnose disorders that mimic stroke and TIA more accurately. Despite the high sensitivity of MRI, a false-negative DWI result can happen during the first $24 \mathrm{~h}$ of PCIS. Posterior ischemic stroke stroke should therefore not be excluded on the basis of early negative DWI, especially when vertebrobasilar suggestive symptoms persist (18). 


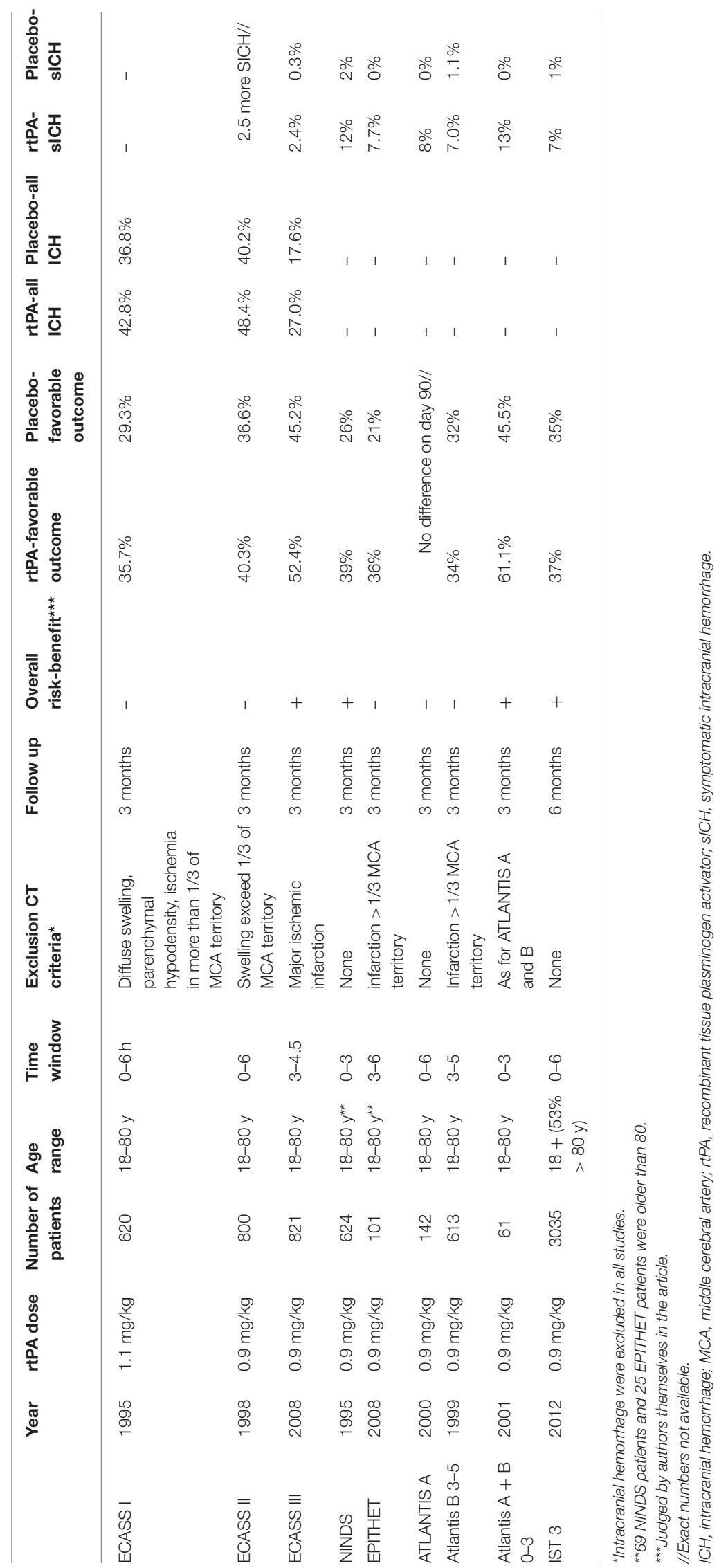


CT angiography (CTA) and time of flight (TOF) magnetic resonance angiography (MRA) have high sensitivity for intracranial stenosis (98 and 70\%, respectively) and occlusion (100 and 87\%, respectively). CTA offers better diagnostic accuracy than TOF MRA and is recommended over TOF MRA for detecting intracranial stenosis and occlusion. CTA has a high interoperator reliability and is superior to DSA in the evaluation of posterior circulation steno-occlusive disease when slow flow is present (33).

Contrast-enhanced MRA has a higher sensitivity than TOFMRA and with similar sensitivity to DSA in ischemic stroke patients. Contrast-enhanced MRA is superior to TOF-MRA in localizing vessel occlusion and assessment of collateral status, providing a larger coverage (extracranial vessels) with shorter acquisition time (34).

In a study of 436 patients with PCIS who underwent perfusion computed tomography (CTP), multiple clinical, etiological, and radiological variables were associated with focal hypoperfusion (20). Focal hypoperfusion was associated with a worse 12 -month outcome (20).

\section{IVT IN POSTERIOR CIRCULATION STROKE Frequency of PCIS in IVT Trials}

PCIS represents $12-19 \%$ of all IVT-treated strokes $(16,35,36)$. Patients with PCIS can could not significantly influenced the results of randomized controlled trials, given that PCIS patients were under-represented in these studies: $5 \%$ of the PCIS patients in the NINDS study and $0 \%$ in the ECASS I and II trials; and there is no information on PCIS representation is available from the ATLANTIS and the ECASS III trials (4-10).

In most of the published studies, stroke territory was classified according to clinical presentation in combination with CT and MRI findings. Proportion of CT and MRI done was not mentioned in most of them (35-37) or only CT findings were taken into account (38). In Dorńák et al. study, control imaging by CT/MRI/none was done on 30/68/2 PCIS patients, respectively, and on 436/329/12 ACIS patients, respectively (16).

\section{Clinical Outcome}

There are some placebo-controlled trials that reported positive effects and benefits of IVT on clinical outcome in ACIS patients $(4-6,12)$. No data on efficacy of IVT in PCIS are available from randomized control studies. Based on the results of only retrospective clinical studies, patients with PCIS had 38-49\% favorable outcomes (mRS 0-1) after IVT $(16,36)$.

Better clinical outcomes after 3 months occur more often (66 vs. $47 \%$ respectively, $P<0.001)$ as well as lower NIHSS scores after 2 and $24 \mathrm{~h}$ in patients with PCIS than in those with ACIS (35, 36). Nevertheless, posterior circulation territory is not associated with favorable outcome after multivariable adjustments in all cause ischemic strokes (36).

Blood glucose level, NIHSS score, age, antiplatelet medication, and anticoagulation are independently associated with a favorable outcome. The initial NIHSS score seems to be less important predictor of outcome than decreased consciousness measured by the Glasgow Coma Scale (39). Mortality rate among
TABLE 2 | Various definitions of symptomatic intracerebral hemorrhage.

\begin{tabular}{lll}
\hline & Clinical & Radiological \\
\hline NINDS & Any & Any \\
ECASS 2 & $\begin{array}{l}\text { Deterioration, adverse } \\
\text { events, or } \geq 4 \text { NIHSS }\end{array}$ & Any \\
ECASS 3 & $\geq 4$ NIHSS & Any \\
SITS-MOST & $\geq 4$ NIHSS & Parenchymal hemorrhage 2
\end{tabular}

NINDS: any ICH not seen on a previous CT scan and subsequently either a suspicion of hemorrhage or any decline in neurologic status. ECASS 2: any $\mathrm{ICH}$ with clinical deterioration, or adverse events indicating clinical worsening (e.g., drowsiness, increase of hemiparesis) or causing a decrease in the NIHSS score of 4 or more points. ECASS 3: any $\mathrm{ICH}$ associated with clinical deterioration, as defined by an increase of 4 points or more in the score on the NIHSS, or that led to death. SITS-MOST: local or remote parenchymal hemorrhage type 2 on the 22-36 h post-treatment imaging scan, combined with a neurological deterioration of 4 points or more on the NIHSS from baseline, or from the lowest NIHSS value between baseline and $24 \mathrm{~h}$, or leading to death.

PCIS patients treated with IVT ranges from 9 to $19 \%(16,36,37)$ and even though it is lower in PCIS, it does not differ significantly between PCIS and ACIS (36).

\section{Definitions and Frequency of $\mathrm{ICH}$ Following IVT}

It is well-known that risk might outweigh benefit beyond $4.5 \mathrm{~h}$ in ACIS. Intracranial hemorrhage is the most feared complication of IVT. It occurs in $0-6.9 \%$ of patients with PCIS, depending on the definition of symptomatic ICH, and any ICH in $17-23.4 \%$ of patients with PCIS (16, 35-37). Table 2 shows various definitions ofsICH. The ECASS 2 and SITS-MOST sICH definitions are said to best identify tPA hemorrhages that alter final patient outcome (40). However, the definition of "symptomatic" raises several concerns. PCIS symptoms are not well-represented by the NIHSS, which is frequently used to categorize ICH (41). In addition, sICH is a subjective term with clinical deterioration that could occur for various other reasons and may be evaluated differently by different physicians or missed if a patient is in coma or mechanically ventilated. For many reasons, symptomatic definitions are not suitable for retrospective studies without tight protocol documentation.

In a study by Sarikaya et al. (36) on 883 consecutive acute stroke patients (out of which 95 were PCIS patients) treated with IVT in three Swiss stroke centers, there were a total of $36(4 \%)$ sICH patients according to NINDS criteria. Patients with PCIS had sICH less often ( 0 vs. $5 \%, P=0.026)$ and PCIS was an independent predictor of a lower frequency of sICH. Another study on 84 PCIS patients demonstrated a trend of increasing incidence of $\mathrm{ICH}$ across various types of sICH $(P$ $=0.0001$ per NINDS, $P=0.001$ per ECASS II, $P=0.002$ per SITS-MOST, and $P=0.008$ for any ICH (35). In a singlecenter study by Dorňák et al. (16) with a similar number of patients, ICH according to ECASS I criteria (independent of clinical manifestation) was significantly less frequent in PCIS than in ACIS patients (5.1 vs. $17.2 \%$, respectively). The risk for ICH was 3.4 times higher in ACIS than in PCIS. In addition, the risk for large hemorrhage $(\mathrm{PH} 1+\mathrm{PH} 2)$ was 5.2 times greater in 
TABLE 3 | Outcome in basilar artery occlusion patients treated with IVT.

\begin{tabular}{|c|c|c|c|c|c|c|c|c|c|}
\hline Study & Year & $n$ & \multicolumn{3}{|c|}{ Modified Rankin Scale } & Mortality (\%) & Time of follow-up & $\mathrm{SICH}(\%)$ & Recanalization rate (\%) \\
\hline & & 50 & 30 & 34 & 20 & 46 & 1 year & & \\
\hline Lindsberg, Mattle* & 2006 & 76 & 22 & $\mathrm{~N} / \mathrm{A}$ & N/A & 50 & Varies & 11 & 53 \\
\hline BASICS-MtM & 2009 & 49 & 53 & 63 & 20 & 16 & 1 month & 6 & 71 \\
\hline Sairanen & 2011 & 116 & 26 & 36 & 22 & 41 & 3 months & 16 & 65 \\
\hline Miyagi\# & 2012 & 25 & 48 & N/A & $\mathrm{N} / \mathrm{A}$ & 4 & 3 months & 8 & 78 \\
\hline
\end{tabular}

BASICS, Basilar Artery International Cooperation Study; MtM, mild to moderate deficit; $n$, number; S, severe deficit; SICH, symptomatic intracranial hemorrhage.

* Systematic review of literature up to 2005.

\#Patients treated with low-dose alteplase $(0.6 \mathrm{mg} / \mathrm{kg})$.

ACIS. No significant difference was observed between ACIS and PCIS for small petechial hemorrhage (HI1 + HI2 per ECASS I).

The reason for low frequency of ICH in PCIS is unknown and rather hypothetical. A smaller lesion volume in infratentorial strokes (42) and better collateral circulation in comparison with the middle cerebral artery (43) as well as the fact that the brainstem is nourished by small end arteries might partly explain the lower sICH occurrence. In addition, pretreatment bloodbrain barrier derangement is an infrequent finding in acute PCIS and may be associated with an increased risk of parenchymal hemorrhage development in patients undergoing recanalization therapy (44).

The lower risk of IVT in PCIS could suggest that the benefit of IVT administration, even beyond $4.5 \mathrm{~h}$ or in borderline cases, may outweigh the potential risk. Borderline cases refer to patients who are relatively indicated/contraindicated because the class (strength) of recommendation is Class IIb or III according to the most recent AHA/ASA recommendations from 2018. Those are the situations where the benefit $=$ or $\geq$ the risk (45). The knowledge of ICH predictors following IVT is thus extremely useful.

\section{ICH Predictors After IVT in PCIS}

Various risk score models have been developed to predict sICH after IVT, but due to the generally low occurrence of PCIS, such scoring systems are mostly designed and tested for ACIS $(46,47)$.

In a study by Sarikaya et al. (36), atrial fibrillation $(P=$ $0.019)$, antiplatelet medication $(P=0.025)$, and diastolic blood pressure $(P=0.029)$ were identified using multivariate logistic regression analyses as independent predictors of sICH according to NINDS criteria. Nevertheless, due to the lack of sICH in PCIS (0\%), no predictors for PCIS could be identified. Undermined logistic regression analyses by the low occurrence of $\mathrm{sICH}$ was a problem in the most of published studies with PCIS patients (16, 35-37, 48). The largest study by Dorňák et al. (49) on 158 PCIS patients has enough patients to identify predictors of $\mathrm{ICH}$ in PCIS. Atrial fibrillation $(p=0.004)$, NIHSS score at time of treatment $(p=0.016)$, decreased level of consciousness $(p=$ $0.003)$, basilar artery occlusion $(p=0.007)$, occlusion of PCA ( $p$ $=0.001)$, and additional endovascular therapy $(p=0.001)$ were identified as significant predictors for ICH (according to ECASS I) in PCIS $(7,49)$.

Supratentorial localization of acute ischemia in the territory of the PCA ( $p=0.025)$ as well as the bigger volume of ischemic changes in this localization $(p=0.025)$ significantly increase the risk of $\mathrm{ICH}$ (49). The brainstem was the only localization out of four established groups (brainstem, cerebellum, thalamus, and supratentorial territory of PCA) that decreased, although statistically not significantly, the risk of ICH $(p=0.545)$ (49).

Time to IVT in PCIS seems to not crucially influence ICH risk or chances for unfavorable outcomes, as it does in ACIS $(49,50)$. IVT for PCIS may be beneficial when initiated even $8 \mathrm{~h}$ after symptom onset $(39,51)$. Thrombolysis $4.5-6 \mathrm{~h}$ after stroke onset reduced infarct growth and increased the rate of reperfusion, which was associated with good neurological and functional outcome (52).

\section{IVT in Basilar Artery Occlusion}

IVT in basilar artery occlusion (BAO) can be used alone or prior to endovascular treatment asa bridging in terms of the "drip, ship, and retrieve" approach. Several studies reported the efficacy of IVT alone, similar to invasive endovascular therapy, reaching a good clinical outcome (mRS $0-2$ ) in $21-53 \%$ of the patients and as mRS $0-3$ in $26-63 \%$ as shown in Table 3 (50). The recanalization rate of IVT alone is $52-78 \%$, and it almost reaches the efficacy of intra-arterial thrombolysis (IAT), which varies from 63 to 94\% (50). Data from the Basilar Artery International Cooperation Study (BASICS) on 592 basilar artery occlusion patients do not support unequivocal superiority of IAT over IVT (53). Brandt et al. (54) suggested that occlusion of distal onethird of the basilar artery is associated with a lower mortality rate than occlusion of proximal and/or middle portions of the basilar artery. Despite the fact that thrombus location in the proximal or middle segments of the basilar artery often result in large pontine strokes with severe deficits, no significant association between localization of occlusion and outcome was reported in several studies $(53,55-57)$.

The bridging approach combines the speed of widely accessible IV agents with the high recanalization rate of endovascular techniques. Metanalyses on 15 studies 
demonstrated that bridging is associated with acceptable safety and efficacy in stroke patients (58). Bridging therapy shortens the time to any specific recanalization treatment, which seems to be the only modifiable independent predictor of both 30-day and 90-day clinical outcome. Thus, additional endovascular treatment should be started as soon as possible and not considered only as a rescue strategy $(57,58)$. Data from two small series on basilar artery occlusion patients (52, respectively 70 patients) reported better 90 -day clinical outcomes in patients treated with bridging $(59,60)$.

\section{CONCLUSION}

Up to date, no data about IVT in PCIS are available from RTCs. Based on limited results from retrospective clinical studies and case series, IVT is safer for use in PCIS than in ACIS. Patients with brainstem ischemia, vertebral artery occlusion, and absence of basilar or posterior cerebral artery occlusion could be considered for treatment with IVT even in borderline cases. Those patients seem to experience favorable outcome less frequently despite not having an increase in $\mathrm{ICH}$ rates. Time to

\section{REFERENCES}

1. Mori E, Yoneda Y, Tabuchi M, Yoshida T, Ohkawa S, Ohsumi Y, et al. Intravenous recombinant tissue plasminogen activator in acute carotid artery territory stroke. Neurology. (1992) 42:976-82. doi: 10.1212/WNL.42.5.976

2. Yamaguchi $\mathrm{T}$, Hayakawa $\mathrm{T}$, Kiuchi $H$. Intravenous tissue plasminogen activator ameliorates the outcome of hyperacute embolic stroke. Cerebrovasc Dis. (1993) 3:269-72. doi: 10.1159/000108714

3. Haley EC Jr., Brott TG, Sheppard GL, Barsan W, Broderick J, Marler JR, et al. Pilot randomized trial of tissue plasminogen activator in acute ischemic stroke. The TPA Bridging Study Group. Stroke. (1993) 24:1000-4. doi: 10.1161/01.STR.24.7.1000

4. National Institute of Neurological Disorders, Stroke rtPA Stroke Study Group. Tissue plasminogen activator for acute ischemic stroke. N Engl J Med. (1995) 333:1581-7. doi: 10.1056/NEJM199512143332401

5. Albers GW, Clark WM, Madden KP, Hamilton SA. ATLANTIS trial: results for patients treated within 3 hours of stroke onset. Alteplase Thrombolysis for Acute Noninterventional Therapy in Ischemic Stroke. Stroke. (2002) 33:493-5. doi: 10.1161/hs0202.102599

6. Hacke W, Kaste M, Bluhmki E, Brozman M, Dávalos A, Guidetti $\mathrm{D}$, et al. Thrombolysis with alteplase 3 to 4.5 hours after acute ischemic stroke. N Engl J Med. (2008) 359:1317-29. doi: 10.1056/NEJMoa0 804656

7. Hacke W, Kaste M, Fieschi C, Toni D, Lesaffre E, von Kummer R, et al. Intravenous thrombolysis with recombinant tissueplasminogen activator for acute hemispheric stroke. The European Cooperative Acute Stroke Study (ECASS). JAMA. (1995) 274:1017-25. doi: 10.1001/jama.1995.03530130023023

8. Hacke W, Kaste M, Fieschi C, von Kummer R, Davalos A, Meier D, et al. Randomised double-blind placebo-controlled trial ofthrombolytic therapy with intravenous alteplase in acute ischemic stroke (ECASS II). Second European-Australasian Acute Stroke Study Investigators. Lancet. (1998) 352:1245-51. doi: 10.1016/S0140-6736(98)08020-9

9. Clark WM, Wissman S, Albers GW, Jhamandas JH, Madden KP, Hamilton S. Recombinant tissue-type plasminogen activator (Alteplase) for ischemic stroke 3 to 5 hours after symptom onset. The ATLANTIS Study: a randomized controlled trial. Alteplase Thrombolysis for Acute Noninterventional Therapy in Ischemic Stroke. JAMA. (1999) 282:2019-26. doi: 10.1001/jama.282.21.2019
IVT in PCIS seems to be a less crucial factor than in ACIS. IVT for PCIS may be beneficial even after $4.5 \mathrm{~h}$ from symptom onset.

\section{AUTHOR CONTRIBUTIONS}

TD conceived the presented idea and wrote the first draft of the manuscript. MK, DŠ, and PK provided critical feedback and helped shape the manuscript.

\section{FUNDING}

This study was conducted on an academic basis and was supported by the AZV CR - Health Research Council of the Czech Republic No. 17-29452A, and 17-30101A; by the institutional support of the Ministry of Health of the Czech Republic MH CZ - DRO (FNOL, 00098892) - 2016, 2017, 2018 and by a grant from the Internal Grant Agency of Palacky University IGA_LF_2018_017 and IGA_LF_2019_010.

\section{ACKNOWLEDGMENTS}

We thank Anne Johnson for the language editing.

10. Clark WM, Albers GW, Madden KP, Hamilton S. The rtPA (alteplase) 0- to 6-hour acute stroke trial, part A (A0276g): results of a double-blind, placebocontrolled, multicenter study. Thromblytic therapy in acute ischemic stroke study investigators. Stroke. (2000) 31:811-6. doi: 10.1161/01.STR.31.4.811

11. Davis SM, Donnan GA, Parsons MW, Levi C, Butcher KS, Peeters A, et al. Effects of alteplase beyond $3 \mathrm{~h}$ after stroke in the Echoplanar Imaging Thrombolytic Evaluation Trial (EPITHET): a placebo-controlled randomised trial. Lancet Neurol. (2008) 7:299-309. doi: 10.1016/S1474-4422(08)70044-9

12. IST-3 Collaborative Group, Sandercock P, Wardlaw JM, Lindley RI, Dennis M, Cohen G, et al. The benefits and harms of intravenous thrombolysis with recombinant tissue plasminogen activator within $6 \mathrm{~h}$ of acute ischemic stroke (the third international stroke trial [IST-3]): a randomised controlled trial. Lancet. (2012) 379:2352-63. doi: 10.1016/S0140-6736(12)60768-5

13. Merwick Á, Werring D. Posterior circulation ischemic stroke. BMJ. (2014) 348:g3175. doi: 10.1136/bmj.g3175

14. Gulli G, Markus HS. The use of FAST and ABCD2 scores in posterior circulation, compared with anterior circulation, stroke and transient ischemic attack. J Neurol Neurosurg Psychiatry. (2012) 83:228-9. doi: 10.1136/jnnp.2010.222091

15. Gulli G, Marquardt L, Rothwell PM, Markus HS. Stroke risk after posterior circulation stroke/transient ischemic attack and its relationship to site of vertebrobasilar stenosis: pooled data analysis from prospective studies. Stroke. (2013) 44:598-604. doi: 10.1161/STROKEAHA.112.669929

16. Dorňák T, Král M, Hazlinger M, Herzig R, Veverka T, Burval S, et al Posterior vs. anterior circulation infarction: demography, outcomes, and frequency of hemorrhage after thrombolysis. Int J Stroke. (2015) 10:1224-8. doi: $10.1111 /$ ijs.12626

17. Tao WD, Liu M, Fisher M, Wang DR, Li J, Furie KL, et al. Posterior versus anterior circulation infarction: how different are the neurological deficits? Stroke. (2012) 43:2060-5. doi: 10.1161/STROKEAHA.112.652420

18. Oppenheim C, Stanescu R, Dormont D, Crozier S, Marro B, Samson Y, et al. False-negative diffusion-weighted MR findings in acute ischemic stroke. Am J Neuroradiol. (2000) 21:1434-40.

19. Flossmann E, Redgrave JN, Briley D, Rothwell PM. Reliability of clinical diagnosis of the symptomatic vascular territory in patients with recent transient ischemic attack or minor stroke. Stroke. (2008) 39:2457-60. doi: 10.1161/STROKEAHA.107.511428

20. Pallesen LP, Lambrou D, Eskandari A, Barlinn J, Barlinn K, Reichmann $\mathrm{H}$, et al. Perfusion computed tomography in posterior circulation stroke: 
predictors and prognostic implications of focal hypoperfusion. Eur J Neurol. (2018) 25:725-31. doi: 10.1111/ene.13578

21. Mattle HP, Arnold M, Lindsberg PJ, SchonewilleWJ, Schroth G. Basilar artery occlusion. Lancet Neurol. (2011) 10:1002-14. doi: 10.1016/S1474-4422(11)70229-0

22. Marinković SV, Gibo $H$. The surgical anatomy of the perforating branches of the basilar artery. Neurosurgery. (1993) 33:80-7. doi: 10.1227/00006123-199307000-00012

23. Frank Netter. Atlas of Human Anatomy. 6th ed. Philadelphia, PA: Saunders (2014).

24. Caplan LR, Wityk RJ, Glass TA, Tapia J, Pazdera L, Chang HM, et al. New England Medical Center Posterior Circulation registry. Ann Neurol. (2004) 56:389-98. doi: 10.1002/ana.20204

25. Caplan L. Posterior circulation ischemia: then, now, and tomorrow. The Thomas Willis Lecture-2000. Stroke. (2000) 31:2011-23. doi: 10.1161/01.STR.31.8.2011

26. Burns JD, Rindler RS, Carr C, Lau H, Cervantes-Arslanian AM, GreenLaRoche DM, et al. Delay in diagnosis of basilar artery stroke. Neurocrit Care. (2016) 24:172-9. doi: 10.1007/s12028-015-0211-0

27. Lee JH, Han SJ, Yun YH, Choi HC, Jung S, Cho SJ, et al. Posterior circulation ischemic stroke in Korean population. Eur J Neurol. (2006) 13:742-8. doi: 10.1111/j.1468-1331.2006.01274.x

28. Britt TB, Bhimji SS. Dissection, Vertebral Artery. Treasure Island, FL: StatPearls Publishing (2018). Available online at: https://www.ncbi.nlm.nih. gov/books/NBK441827/ (accessed November 2, 2018).

29. Nor AM, Davis J, Sen B, Shipsey D, LouwSJ, Dyker AG, et al. The Recognition of Stroke in the Emergency Room (ROSIER) scale: development and validation of a stroke recognition instrument. Lancet Neurol. (2005) 4:727-34. doi: 10.1016/S1474-4422(05)70201-5

30. Olivato S, Nizzoli S, Cavazzuti M, Casoni F, Nichelli PF, Zini A. e-NIHSS: an expanded national institutes of health stroke scale weighted for anterior and posterior circulation strokes. J Stroke Cerebrovasc Dis. (2016) 25:2953-7. doi: 10.1016/j.jstrokecerebrovasdis.2016.08.011

31. Chalela JA, Kidwell CS, NentwichLM, Luby M, Butman JA, Demchuk AM, et al. Magnetic resonance imaging and computed tomography in emergency assessment of patients with suspected acute stroke: a prospective comparison. Lancet. (2007) 369:293-8. doi: 10.1016/S0140-6736(07)60151-2

32. Rudkin S, Cerejo R, Tayal A, Goldberg MF. Imaging of acute ischemic stroke. Emerg Radiol. (2018) 25:659-72. doi: 10.1007/s10140-018-1623-x

33. Bash S, Villablanca JP, Jahan R, Duckwiler G, Tillis M, Kidwell C, et al. Intracranial vascular stenosis and occlusive disease: evaluation with CT angiography, MR angiography, and digital subtraction angiography. Am J Neuroradiol. (2005) 26:1012-21.

34. Boujan T, Neuberger U, Pfaff J, Nagel S, Herweh C, Bendszus M, Möhlenbruch MA. Value of contrast-enhanced MRA versus time-of-flight MRA in acute ischemic stroke MRI. Am J Neuroradiol. (2018) 39:1710-6. doi: 10.3174/ajnr.A5771

35. Sung SF, Chen $\mathrm{CH}$, Chen YW, Tseng MC, Shen HC, Lin HJ. Predicting symptomatic intracerebral hemorrhage after intravenous thrombolysis: stroke territory as a potential pitfall. J Neurol Sci. (2013) 335:96-100. doi: 10.1016/j.jns.2013.08.036

36. Sarikaya H, Arnold M, Engelter ST, Lyrer PA, Mattle HP, Georgiadis D, et al. Outcomes of intravenous thrombolysis in posterior versus anterior circulation stroke. Stroke. (2011) 42:2498-502. doi: 10.1161/STROKEAHA.110.607614

37. Förster A, Gass A, Kern R, Griebe M, Hennerici MG, Szabo K. Thrombolysis in posterior circulation stroke: stroke subtypes and patterns, complications and outcome. Cerebrovasc Dis. (2011) 32:349-53. doi: 10.1159/000330346

38. Valentino F, Gentile L, Terruso V, Mastrilli S, Aridon P, Ragonese P, et al. Frequency and determinants for hemorrhagic transformation of posterior cerebral stroke : posterior ischemic stroke and hemorrhagic transformation. BMC Res Notes. (2017) 10:592. doi: 10.1186/s13104-017-2889-x

39. Tsao JW, Hemphill JC III, Johnston SC, Smith WS, Bonovich DC. Initial Glasgow Coma Scale score predicts outcome following thrombolysis for posterior circulation stroke. Arch Neurol. (2005) 62:1126-9. doi: 10.1001/archneur.62.7.1126

40. Rao NM, Levine SR, Gornbein JA, Saver JL. Defining clinically relevant cerebral hemorrhage after thrombolytic therapy for stroke: analysis of the National Institute of Neurological Disorders and Stroke tissue-type plasminogen activator trials. Stroke. (2014) 45:2728-33. doi: 10.1161/STROKEAHA.114.005135

41. Sato S, Toyoda K, Uehara T, Toratani N, Yokota C, Moriwaki $\mathrm{H}$, et al. Baseline NIH Stroke Scale Score predicting outcome in anterior and posterior circulation strokes. Neurology. (2008) 70:2371-7. doi: 10.1212/01.wnl.0000304346.14354.0b

42. Lindgren A, Norrving B, Rudling O, Johansson BB. Comparison of clinical and neuroradiological findings in first-ever stroke. A population-based study. Stroke. (1994) 25:1371-7.

43. Menon BK, O'Brien B, Bivard A, Spratt NJ, Demchuk AM, Miteff F, et al. Assessment of leptomeningeal collaterals using dynamic CT angiography in patients with acute ischemic stroke. J Cereb Blood Flow Metab. (2013) 33:365-71. doi: 10.1038/jcbfm.2012.171

44. Lee M, Saver JL, Alger JR, Hao Q, Starkman S, Ali LK, et al. Blood-brain barrier permeability derangements in posterior circulation ischemic stroke: frequency and relation to hemorrhagic transformation. J Neurol Sci. (2012) 313:142-6. doi: 10.1016/j.jns.2011.08.048

45. Powers WJ, Rabinstein AA, Ackerson T, Adeoye OM, Bambakidis NC, Becker $\mathrm{K}$, et al. 2018 guidelines for the early management of patients with acute ischemic stroke: a guideline for healthcare professionals from the American Heart Association/American Stroke Association. Stroke. (2018) 49:e46-110. doi: 10.1161/STR.0000000000000158

46. Sung SF, Chen SC, Lin HJ, Chen YW, Tseng MC, Chen CH. Comparison of risk-scoring systems in predicting symptomatic intracerebral hemorrhage after intravenous thrombolysis. Stroke. (2013) 44:1561-6. doi: 10.1161/STROKEAHA.111.000651

47. Asuzu D, Nystrom K, Amin H, Schindler J, Wira C, Greer D, et al. Comparison of 8 scores for predicting symptomatic intracerebral hemorrhage after IV thrombolysis. Neurocrit Care. (2015) 22:229-33. doi: 10.1007/s12028-014-0060-2

48. Tong X, Liao X, Pan Y, Cao Y, Wang C, Liu L, et al. Intravenous thrombolysis is more safe and effective for posterior circulation stroke: data from the Thrombolysis Implementation and Monitor of Acute Ischemic Stroke in China (TIMS-China). Medicine. (2016) 95:e3848. doi: 10.1097/MD.0000000000003848

49. Dorňák T, Král M, Sedláčková Z, Šanák D, Cecháková E, Divišová $\mathrm{P}$, et al. Predictors for intracranial hemorrhage following intravenous thrombolysis in posterior circulation stroke. Transl Stroke Res. (2018) 9:582-8. doi: 10.1007/s12975-018-0608-0

50. Dorňák T, Herzig R, Šanák D, Školoudík D. Management of acute basilar artery occlusion: should any treatment strategy prevail? Biomed Pap Med Fac Univ Palacky Olomouc Czech Repub. (2014) 58:528-34. doi: 10.5507/bp.2013.075

51. Montavont A, Nighoghossian N, Derex L, Hermier M, Honnorat J, PhilippeauF, et al. Intravenous r-TPA in vertebrobasilar acute infarcts. Neurology. (2004) 62:1854-6. doi: 10.1212/01.WNL.0000125330.06520.0D

52. Picanço MR, Christensen S, Campbell BC, Churilov L, Parsons MW, Desmond PM, et al. Reperfusion after 4.5 hours reduces infarct growth and improves clinical outcomes. Int J Stroke. (2014) 9:266-9. doi: 10.1111/ijs.12209

53. Schonewille WJ, Wijman CA, Michel P, Rueckert CM, Weimar C, Mattle HP, et al. Treatment and outcomes of acute basilar artery occlusion in the Basilar Artery International Cooperation Study (BASICS): a prospective registry study. Lancet Neurol. (2009) 8:724-30. doi: 10.1016/S1474-4422(09)70173-5

54. Brandt T, von Kummer R, Müller-Küppers M, Hacke W. Thrombolytic therapy of acute basilar artery occlusion. Variables affecting recanalization and outcome. Stroke. (1996) 27:875-81.

55. Jung S, Mono ML, Fischer U, Galimanis A, Findling O, De Marchis GM, et al. Three-month and long-term outcomes and their predictors in acute basilar artery occlusion treated with intra-arterial thrombolysis. Stroke. (2011) 42:1946-51. doi: 10.1161/STROKEAHA.110.606038

56. Sairanen T, Strbian D, Soinne L, Silvennoinen $H$, Salonen O, Artto V, et al. Intravenous thrombolysis of basilar artery occlusion: predictors of recanalization and outcome. Stroke. (2011) 42:2175-9. doi: 10.1161/STROKEAHA.110.605584

57. Dorňák T, Herzig R, Kuliha M, Havlíček R, Školoudík D, Šanák D, et al. Endovascular treatment of acute basilar artery occlusion: time to treatment is crucial. Clin Radiol. (2015) 70:e20-7. doi: 10.1016/j.crad.2015. 01.008 
58. Mazighi M, Meseguer E, Labreuche J, Amarenco P. Bridging therapy in acute ischemic stroke: a systematic review and meta-analysis. Stroke. (2012) 43:1302-8. doi: 10.1161/STROKEAHA.111.635029

59. Dorňák T, Herzig R, Školoudík D, Šanák D, Kuliha M, Roubec M, et al. Outcome predictors in acute basilar artery occlusion. Can J Neurol Sci. (2014) 41:368-74. doi: 10.1017/S0317167100017327

60. Pfefferkorn T, Holtmannspötter M, Schmidt C, Bender A, Pfister HW, Straube A, et al. Drip, ship, and retrieve: cooperative recanalization therapy in acute basilar artery occlusion. Stroke. (2010) 41:722-6. doi: 10.1161/STROKEAHA.109.5
Conflict of Interest Statement: The authors declare that the research was conducted in the absence of any commercial or financial relationships that could be construed as a potential conflict of interest.

Copyright (c) 2019 Dorňák, Král, Šaňák and Kaňovský. This is an open-access article distributed under the terms of the Creative Commons Attribution License (CC BY). The use, distribution or reproduction in other forums is permitted, provided the original author(s) and the copyright owner(s) are credited and that the original publication in this journal is cited, in accordance with accepted academic practice. No use, distribution or reproduction is permitted which does not comply with these terms. 